\title{
"Murphy's Cousin" (Solanum triflorum)
}

by Keith Best and Archie Budd, Swift Current

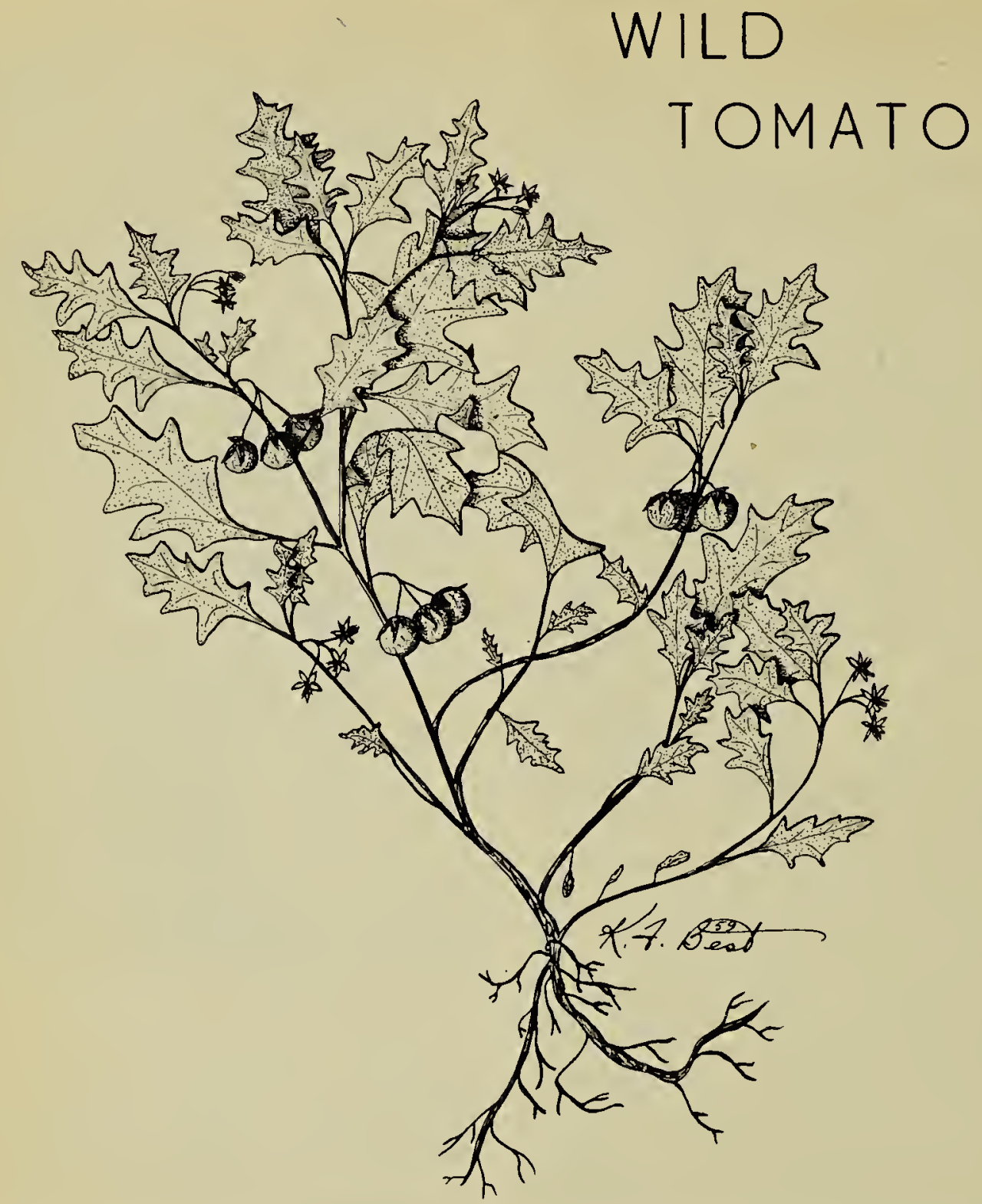

The majority, if not all, members of the Solanaceae or potato family have certain poisonous properties. The foliage and the fruit of the potato are poisonous and the foliage of tomatoes should not be eaten. Our Saskatchewan native of this family is the Wild Tomato or Threeflowered Nightshade (Solanum triflorum). This plant is an almost prostrate, hairy annual with leaves from one to three inches long and very deeply lobed. The flowers are rotate, from a quarter to threeeighths of an inch in diameter and white in colour. They resemble very small potato flowers and are, of course, in the same genus. The fruit is a small globose berry about half an inch in diameter and of a dull green colour.

Before the settlement of the prairies this weed was found on disturbed soil such as badger or gopher mounds or the eroded trails to fords or water holes and so it has some- times been called "dog-town weed." When the homesteaders came it found ideal conditions on fireguards and in farm gardens where it became very plentiful.

In addition to being a "moisture greedy" weed this plant has other bad characteristics. Its succulence makes it difficult to destroy and the large, flat plants of Wild Tomato when hoed or pulled out and turned upside down will send out numerous tiny, white, adventitious rootlets from the stems if the soil is at all moist, anchor themselves and continue to mature. It is also a host of the Colorado potato beetle or "potato bug" and helps to ensure the survival of these pests in the absence of potatoes.

While the ripe fruit was used as food by the Indians and many of the homesteaders relished it. when made into jam or preserves, some folk found it badly upset their stomachs, the writer being amongst these. 